\title{
A complex association of cardiomyopathy, mild dysmorphisms and leukoencephalopathy
}

Uma associação complexa de cardiomiopatia, dismorfismos discretos e leucoencefalopatia

Paulo Victor Sgobbi de SOUZA`, Luiz Henrique Libardi SILVA`, Bruno de Mattos Lombardi BADIA`, Igor Braga FARIAS', Wladimir Bocca Vieira de Rezende PINTO', Acary Souza Bulle OLIVEIRA'

A 44-year-old woman presented with a 15-year history of ataxic gait. Medical history disclosed global developmental delay and supravalvular aortic stenosis and persistent arterial duct. Examination showed facial dysmorphisms (dysmorphic ears, broad nose, ocular hypertelorism), dysbasia and bilateral dysmetria. Neuroimaging studies disclosed diffuse leukoencephalopathy (Figures 1 and 2). Whole-exome sequencing was unremarkable. Microarray-based Comparative Genomic
Hybridization disclosed 9p24.3 duplication, diagnosing partial trisomy 9p syndrome.

Partial trisomy 9p syndrome is a common chromosomal disorder associated with facial and appendicular dysmorphisms, congenital cardiopathy, cognitive and motor compromise ${ }^{1,2}$, and different patterns of neuroimaging disturbances, including neuronal migration disorders, Dandy-Walker malformation $^{1,2}$ and leukoencephalopathy, as presented here.

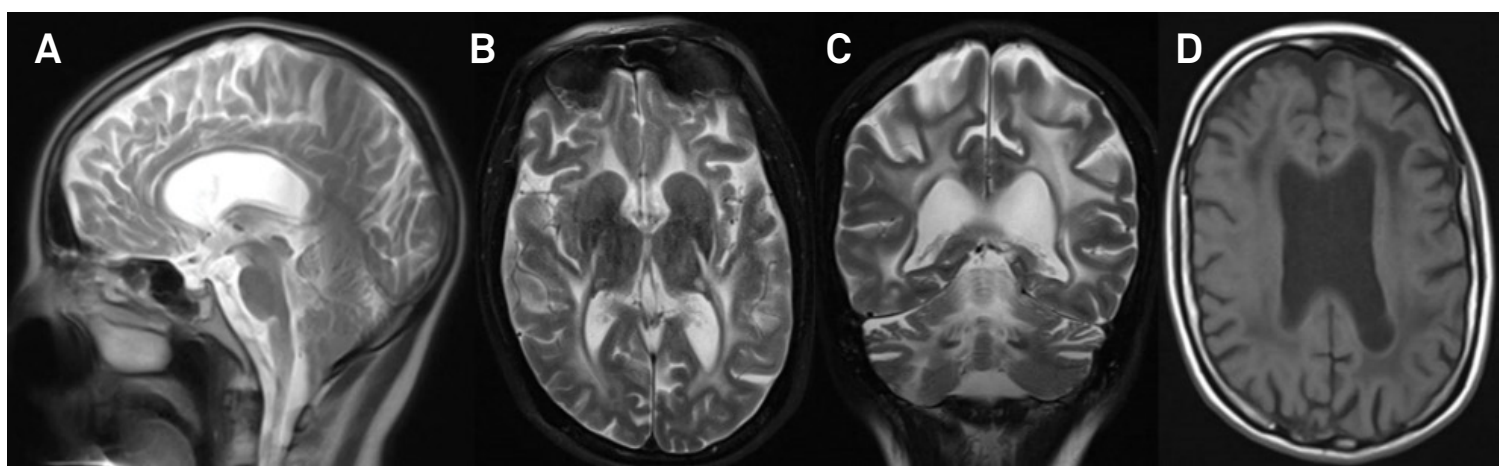

Figure 1. Neuroimaging findings in partial trisomy 9 p syndrome. Sagittal (A), axial (B) and coronal (C) brain MRI disclosing thin corpus callosum and diffuse hyperintensity of periventricular, deep and subcortical cerebral and cerebellar white matter in T2-weighted sequences with corresponding hypointensity in T1-weighted sequence (D).

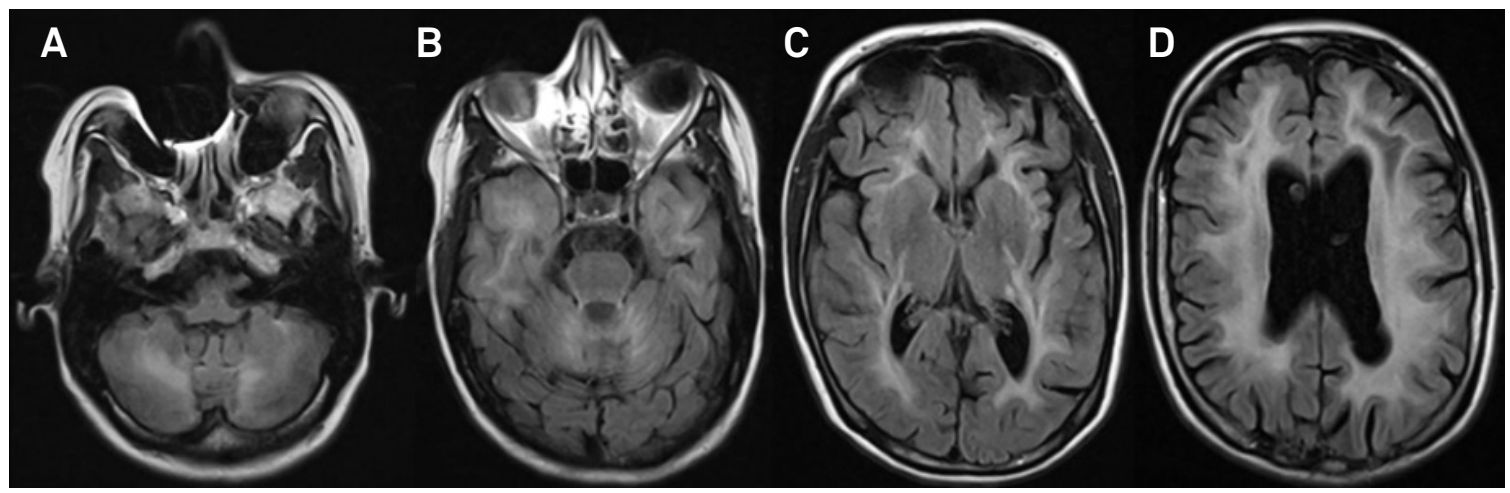

Figure 2. (A-D) Axial brain MRI showing marked white matter involvement in cerebellar, superior cerebellar peduncle and anterior temporal pole, and diffuse hyperintensity of periventricular, deep and subcortical cerebral white matter in FLAIR sequences.

\footnotetext{
1 Universidade Federal de São Paulo, Departamento de Neurologia e Neurocirurgia, São Paulo SP, Brasil. Wladimir Bocca Vieira de Rezende Pinto (iD) http://orcid.org/0000-0002-0150-525X

Correspondence: Wladimir Bocca Vieira de Rezende Pinto; Departamento de Neurologia e Neurocirurgia da UNIFESP; Rua Estado de Israel, 899 ; $04022-002$ São Paulo SP, Brasil; E-mail: wladimirbvrpinto@gmail.com

Conflict of interest: There is no conflict of interest to declare.

Received 15 December 2018; Accepted 15 January 2019
} 


\section{References}

1. Guilherme RS, Meloni VA, Perez AB, Pilla AL, Ramos MA, Dantas AG, et al. Duplication $9 p$ and their implication to phenotype. BMC Med Genet 2014 Dec;15:142. https://doi.org/10.1186/s12881-014-0142-1
2.

Federico A, Tomasetti P, Zollino M, Diomedi M, Dotti MT, De Stefano N, et al. Association of trisomy $9 p$ and band heterotopia. Neurology 1999;53(2):430-2. 